TRANSACTIONS

OF

\title{
THE ROYAL SOCIETY OF EDINBURGH
}


No. 1 Published 21 December 1977

21 December 1977

21 December 1977

31 December 1978

19 October 1979

19 October 1979

19 October 1979
No. 8 Published 19 October 1979

19 October 1979

29 November 1979

29 November 1979

29 November 1979

31 December 1979

31 December 1979 


\title{
TRANSACTIONS
}

\author{
OF

\section{THE ROYAL SOCIETY OF EDINBURGH}

VOL. 70

PUBLISHED BY THE ROYAL SOCIETY OF EDINBURGH 22 GEORGE STREET, EDINBURGH EH2 2 PQ 


\section{Instructions to authors}

As from 1980 (Vol. 71) the Transactions of the Royal Society of Edinburgh: Earth Sciences will appear quarterly, publishing studies on all aspects of the earth sciences and related planetary sciences. Substantial contributions to both information and understanding that emphasise principles and are relevant to a worldwide readership are welcome. Normally there will be an upper limit of 25000 words, but most contributions are expected to be shorter. Discussions of papers previously published in the Transactions and reviews of topics of current interest are also invited. There are no page charges but subventions towards cost would be welcome. If the use of foldouts, colour illustrations, extensive photographic or tabular material is envisaged, the Editorial Office should be consulted prior to submission.

\section{Submission}

Membership of the Society is not a pre-requisite for submission. Three copies of manuscripts should be sent to the Editorial Office, The Royal Society of Edinburgh, 22 George Street, Edinburgh EH2 2PQ, Scotland. Copies of illustrations should also be submitted in triplicate. One set should be in a form ready for reproduction (see 3.1) and the other sets at suggested publication size. Original line drawings may be requested subsequently. All submissions will be sent to two reviewers.

\section{Preparation of papers \\ 2.1. Manuscripts}

Manuscripts should be typed on A4 $(295 \times 210 \mathrm{~mm})$ or quarto paper with double spacing throughout and wide margins. A title that is concise and informative, a heading of not more than 50 typewriter strokes for use at the top of text pages and name(s) of author(s) are to be given on the first page. An abstract of not more than $\mathbf{2 0 0}$ words, intelligible without reference to the text or references, should be given on the second page, with a list of key words not in the title making up no more than 150 typewriter strokes. The text should begin on the third page. Where possible, annotated illustrations and tables should be used in place of text. Give full postal address(es) at the end of the references. Tables and a list of figure captions should be on separate pages.

Editorial details. Words to be printed in italics, e.g. names of taxa, should be underlined. Use capital letters for formal terms only, in both text and headings. The metric system should be used throughout. Abbreviations should omit the full-stop, e.g. $2 \mathrm{~mm}, 3 \mathrm{~km}$ and $6 \mathrm{~kb}$. Compass points are to be abbreviated to N, NW, NW-SE etc. Map references should be in square brackets, e.g. [NM 4437 0293]. Do not use footnotes except in tables. Examples of references in the text are (James 1931), (Jennings \& Smith 1967, p. 132) and (Jenkins 1947, 1950; Jack 1975). Indicate in the margins approximate positions for insertion of illustrations and tables. For particular treatment of palaeontological specialities consult Palaeontology 15, 676-81.

\subsection{Headings}

Primary headings, including Acknowledgements and References, are to be numbered 1, 2, 3 etc. (as in these Instructions) and secondary headings $1.1,1.2,1.3$ etc.; these are to begin at the left-hand margin and should not be underlined. Show tertiary headings by wavy underlining. These should be indented and followed by a full-stop, four spaces and then the text of the sub-section. The introductory section requires no heading. Cross-references in the text should be to a section or sub-section, e.g. (see 2.3), not to a page.

\section{Illustrations and tables}

\subsection{Illustrations}

Illustrations, labelled figures (Fig. 1, 2, 3 etc.) will be reproduced within the body of the text at column $(85 \mathrm{~mm})$ or page $(177 \mathrm{~mm})$ width, or page length $(253 \mathrm{~mm})$, but allowance must be made for figure captions. Where appropriate, group material into one figure and label a, b, c etc. Line drawings should be prepared at $\times 2$ (linear) reproduction size with no lettering on the original less than $3 \mathrm{~mm}$ high (the use of capital letters throughout improves clarity after reduction). Transfer lettering is preferred. Large figures can be subdivided for reproduction on facing pages. Photographs should be high quality glossy prints with good contrast at final size and with a scale, or magnification in the caption. In the case of fossil illustrations illumination should be top left. In certain circumstances (after consultation) photographs will be reproduced on art paper and should be made up as full-page figures.

\subsection{Tables}

Tables $(1,2,3$ etc.) will be set up in type and reproduced at column or page width. Each table should have a heading and be typed on a separate sheet.

\section{References}

Set out as indicated below. Abbreviate journal and series titles according to Part 2 (1975) of BS 4148 (The abbreviation of titles of periodicals. Word-abbreviation list. London: British Standards Institution). This system uses capitals throughout and no full-stops. Indicate volume numbers of journals and series by wavy underlining and book titles by single underlining.

Amstutz, G. C. 1968. Spilites and Spilitic Rocks. In Hess, H. H. \& Poldervaart, A. (eds) Basalts, 737-53. New York: Interscience.

Dick, J. R. F. 1978. On the Carboniferous shark Tristychius arcuatus Agassiz from Scotland. TRANS R SOC EDINBURGH 70, 63-109.

Duff, K. L. 1978. Bivalvia from the English Lower Oxford Clay (Middle Jurassic). PALAEONTOGR SOC MONOGR.

Ferguson, J. \& Currie, K. L. 1971. Evidence of liquid immiscibility in ultrabasic dikes, Ontario. J PETROL 12, 501-85.

Hatch, F. H., Wells, A. K. \& Wells, M. K. 1972. Petrology of the Igneous Rocks, 13th edn. London: George Allen \& Unwin.

\section{Proofs and offprints}

One set of proofs will be sent to the author (or senior author of a joint paper). Fifty free offprints are provided and additional copies can be ordered when proofs are returned. 


\section{TRANSACTIONS OF \\ THE ROYAL SOCIETY OF EDINBURGH}

VOLUME 70, 1979

13. Correlation of middle and upper Proterozoic strata of the northern rim of the North Atlantic craton. By Grant M. Young.

Issued December 31, 1979

14. The Devonian actinopterygian Cheirolepis Agassiz. By D. Michael Pearson and T. Stanley Westoll.

Issued December 31, 1979

Fellows of the Society purchasing publications for their own use will be allowed a special discount of $33 \frac{1}{2}$ per cent on the current prices (see Law 25).

Printed in Scotland

by $T$. and A. Constable Ltd., Hopetoun Street, Edinburgh EH7 4 NF 